cional que regula las relaciones entre el hombre y su medio. Junto a este fenómeno aparece una estructura social fuertemente jerarquizada, inserta en un modelo de hábitat que vendrá a definir los espacios urbanos, nacidos al calor de las nuevas estrategias económicas, basadas en la cada vez mayor especialización de las actividades productivas, en donde los productos orientalizantes alcanzarán un significado de primer orden a la hora de hablar del proceso político interno de las comunidades ibéricas.

Para finalizar, quisiera señalar que las formulaciones, tanto metodológicas como teóricas, mantenidas por los distintos especialistas a lo largo de las dos jornadas que ha durado el seminario, contribuyen a ordenar los principios rectores que rigen la labor del arqueólogo, para ilustrarnos en una serie de interpretaciones que, a la luz que nos ofrece la documentación arqueológica hallada hasta la fecha, examinan los diferentes estadios de desarrollo de los lugares de culto aparecido en la Península Ibérica a lo largo de la Antigüedad, y que se en- cuentran en estrecha relación con el resto del mundo mediterráneo. En este horizonte explicativo, la historia de validez a las relaciones "interculturales", sometidas a la dialéctica de su propio contexto evolutivo, dando paso a sistemas ideológicos, fuertemente anclados en concepciones religiosas que determinarán unos rituales y unas prácticas concretas.

En esta interacción de elementos estructurales, la fundamentación religiosa de las sociedades procedentes del Mediterráneo oriental: fenicio-púnica y griega, así como las desarrolladas en la Península Ibérica: tartésica e ibérica, y, finalmente, la romana, activarán un proceso organizativo de los modelos de asentamiento, entendidos como la expresión más clara de unos factores económicos e ideológicos cada vez más complejos. En este marco conceptual ha de ser analizado el papel que juega cada sector humano, dentro del cual la aristocracia indígena se irá consolidando como grupo social que, mediante la implantación del Poder, hace efectivas unas rela- ciones basadas en los factores productivos que posibilitan la creación de circuitos comerciales, que se extenderán más allá de los límites regionales. En este juego de intereses, la élite y la heroización del individuo definen y fijan unos valores morales que articulan las relaciones del grupo, inserto en unos ritos cultuales que se manifiestan en el terreno de lo mágico y sobrenatural, regulando las relaciones entre el mundo de los vivos y el de los dioses, a los que el hombre se entrega con la esperanza de que sus actos adquieran validez a través de la mediación divina.

\section{Liliane $M^{\mathrm{a}}$ Dahlmann Centro Municipal de Patrimonio Histórico.} Puerto de Sta. María, Cádiz

El Encuentro Templos y Espacios Sagrados Fenicios y Orientalizantes: Ideología, Poder y Socioeconomía se celebró en El Puerto de Sta. María entre el 22 y 24 de marzo de 2000, en el marco de los IV Encuentros de Primavera de la Universidad de Cádiz

\title{
Nuevos Desafíos en la Investigación sobre Sistemas de Información y Representación del Conocimiento
}

El objeto de investigación tradicional en Información y Documentación ha sufrido, en el último decenio, convulsiones y mudanzas de mayor calado que en todo un siglo de historia desde que esta disciplina fuera fundada en Occidente por el belga Paul Otlet en plena época positivista, plagada de consignas maquinistas y expansionistas que tan irreversiblemente han dañado otras culturas y civilizaciones.

El pensamiento dirigido a la organización y transferencia de conocimiento en depósitos convencionales al servicio de eruditos ha sido alterado hoy por nuevos elementos que también transforman los modos de observar y los instrumentos de descripción. Por ello, el aparato teórico-conceptual clásico ha de enriquecerse buscando nuevas alianzas entre los saberes constituidos mutando consecuentemente, uno de los objetivos persistentes de la Ciencia de la Información cual era la consolidación de su estatuto científico. De hecho, a estas alturas debemos pensar más en configuraciones transdisciplinares para solucionar problemas que en Ciencias estancas, en buscar los por qué (las causas) y para qué (intenciones) a la vez que los cómo (métodos) y los efectos.

La nueva situación que hemos de afrontar surge de la irrupción de las tecnologías en los sistemas de información tradicionales, en todas sus tipologías y niveles de operación: bibliotecas, archivos, museos, bases de conocimiento, centros documentales. Como consecuencia inmediata, puede constatarse una creciente presencia de nuevos conceptos clave en el lenguaje epistemológico de nuestro campo de conocimiento: sociedad de la información, comunidades, sistemas federados de conocimiento, gestión de usuarios, modelos de explotación, protocolos de telecomunicaciones, portales, nuevos públicos, elementos que, desde una perspectiva rentabilista a la que nos arrastra la política científca de la Unión europea determinada por los mercados, orientan la investigación de la información y la documentación en el ámbito de los estudios tecnoculturales y de la llamada Nueva economía de la Información.

La red de telecomunicaciones Internet ha supuesto una distribución diferente y desconocida del agros del conocimiento y de la cultura de masas: diferente porque hasta ahora nunca se ha había procedido a una democratización semejante ni a una participación sin límites, ni fronteras, a priori, en ninguna actividad de la especie humana; desconocida porque su expansión horizontal y en profundidad no ha hecho más que empezar. Las materias primas y los servicios tecnosimbólicos que ofrece la red, a la codicia de hoy, surgen como las suculentas minas de oro y plata a los ojos de nues- 
tros antepasados conquistadores, colonos y corsarios. No es por ello de extrañar que en las prioridades de la UE sobre Sociedad de la Información el pensamiento teórico y social haya sido relegado por las aplicaciones, por la visibilidad de la explotación de productos y por la penetración, osadía y competencia de los consorcios en los mercados.

La materia prima de nuestros estudios es la información sin restricciones. Y este es el primer problema epistemológico que emerge en nuestra disciplina: todos manejamos la noción de información sin darle un anclaje consistente. A lo sumo, partimos de una visión empírica del concepto $y$, de hecho, en cualquier foro científco, profesional o coloquial surge este término complejo, diverso y, a veces contradictorio. La Información se confunde, en nuestro ámbito de conocimiento con la Comunicación y con el Periodismo. Empero, la Información interacciona con, y participa de todos ellos, tiene sus propias características diferenciales: desde luego no es equivalente a Periodismo ya que esto es una reducción tipológica. Tampoco puede identificarse con la Comunicación pues la Información se advierte sólo unidireccionalmente $y$, además, frecuentemente se confunde con el conocimiento desde una perspectiva de la recepción, mezclándose un proceso (la información) con un objeto (los datos) y con un objetivo, sea o no intencional: transformar un estado de conocimiento. Vemos con esta simplificación deliberada, la paradoja conceptual en la que nos encontramos cuando hablamos de Sociedad de la Información como estructura virtual dominada por un neomaquinismo $\mathrm{o}$, si lo prefieren, cibermaquinismo.

En este sentido, la Información trivializada es una espada de Damocles en manos del ciudadano ingenuo que cree, precisamente, en la bondad y asepsia de una red electrónica que le está formando como leal consumidor. Por un lado, nuestro ciudadano se siente, por primera vez, dueño de su destino massmediático: es, simultáneamente, receptor de mensajes y datos masivos y emisor de informaciones que pueden llegar a grandes audiencias. Su poder de comunicación y, por ende, de persuasión, es, teóricamente, tan poderoso como el de los flujos propagandísticos, simbólicos y comerciales de los que es objetivo. Salvando las evidentes ventajas de una red global y tecnocultural, el ciudadano es objeto de seducción por parte de Portales, Webs y Buscadores que le invitan a participar en el pastel comunicativo sin contrapartidas aparentes.

Pero esta presunción apocalíptica no es condenatoria y mucho menos pretende negar la red. Por el contrario, me sumo a la evidencia de que el sistema electrónico de información global es el mayor avance de la humanidad en materia de interacción comunicativa. Por tanto, el tono -si me permiten- agorero de mis palabras se basa en la convicción de que Internet no va a librarse de una lucha cainita que ya ha comenzado, en la sospecha de que los nuevos teleconquistadores y telecolonos, apoyados en virreinatos virtuales $y$ teleencomiendas no van a tener actitudes muy distintas a las de nuestros antepasados. $Y$ en definitiva, esos territorios emergentes en el universo virtual van a ser, en los próximos años, objeto de investigación prioritaria para la Ciencia de la Información, transdisciplina que se reconfigura como nuevo campo de observación y descripción tecnocultural: las ideas, la cultura y el conocimiento son cada vez menos separables de las máquinas y de sus sistemas de transmisión.

A pesar de ello, la Nueva Economía de la Información bascula entre varios extremos: por un lado promueve la cultura de la subrogación como única forma de conservación y preservación de nuestros bienes culturales; por otro lado, lo virtual no deja de ser un sucedáneo, única vía que permite el acceso democrático y masivo al conocimiento de objetos culturales digitalizados. No vemos pipas, como diría el genial Magritte sino representaciones electrónicas con todas las reducciones que implican. ¿De qué manera afectará esto nuestro sentido y nuestra sensibilidad y percepciones del mundo físico real?

La detección y descripción de esa fenomenología en el ámbito global nos permite cumplir con el objetivo pragmático de nuestros saberes: la propuesta de mecanismos, métodos y dispositivos lógico-semánticos y cognitivos que coadyuven a la resolución de problemas de orden comunicativo, es decir de persuasión, in- terpretación y representación, en un mercado mundial de información. La tecnocultura se desarrolla en nuevos espacios virtuales en los que vuelven a reproducirse viejos esquemas y símbolos hegemónicos. La reforma de este agros, necesita códigos técnicos (y no políticos) reguladores e instrumentos de orientación apropiados. A los que reflexionan y operan con la Información/Documentación nos corresponde dar respuesta a esta necesidad antrópica y ancestral: la construcción de herramientas y procedimientos de labranza para estas nuevas tierras, desde un modelo demointeractivo que permita una observación compleja e integral de ciudadanos, medios y contenidos.

No debo pasar por alto el sentido del término globalización en nuestros días ya que, en los sistemas de información, adquiere su pleno significado. Muchos jóvenes nacidos en los años finales de la guerra fría intuyen y advierten, en la vertiente ecónomica del término, consecuencias negativas y lo han demostrado violentamente en Seattle y en el primero de mayo pasado en varias capitales europeas. Lo global genera una paradójica respuesta negativa, mayoritariamente entre jóvenes adictos a Internet que se organizan y citan a través de la red para protestar contra el sistema. El talón de Aquiles de Internet. He ahí otro espacio de vital interés para la reflexión teórica en nuestra disciplina.

Por otro lado, cuando empleamos la noción de lo global nos referimos, por defecto, a lo occidental o, en todo caso, a lo mundial desde una óptica y una posición tradicional e interesadamente hegemónica occidental. De hecho, la Economía de la Información beneficia a los países industrialmente dominantes, los que la dictan y aplican y en absoluto se piensa, más que en términos de pequeños porcentajes de consumidores, en los casi dos centenares de países que tienen como principales problemas: la deuda externa, hambrunas, explosión demográfica, enfermedades y catástrofes naturales. La ingenuidad negropontina (la superación de la pobreza mediante Internet) no deja de connotar un hiriente sarcasmo.

De hecho, cuando hablamos de Sociedad de la Información, sector estratégico de investi- 


\section{Noticias y Comentarios}

gación en el $V$ Programa Marco de la UE, pensamos en términos de competencia con Estados Unidos y Japón y en la mejora de las infraestructuras para que los públicos europeos están bien informados, sobre todo, comercialmente. Pero ¿Quién piensa en esos millones de desinformados y analfabetos al otro lado de la cuenca mediterránea? Allí donde no hay resistencia cultural organizada no puede competirse $o$, al menos, tener capacidad crítica y filtros para hacer frente al dominio de Yahoo, de Lycos o de Terra (Terra Livre como ha dado en llamar Telefónica a su filial en Brasil para hacer soñar a los varias veces conquistados). Pequeños segmentos de población africana, algo mayores en América Latina, pasarán a la era posindustrial del Internet II sin saber lo que fue la tarjeta perforada. La mayoría de estas poblaciones analfabetas será atravesada por ondas ciberculturales sin haber visto una fotocopiadora.

Incluso en el propio territorio europeo, ciudadanías como la andaluza no tienen capacidad de reacción y respuesta ante estas nuevas tecnologías impulsadas por los índices bursátiles. La nueva tecnocultura se les escapa y la democratización del acceso es una falacia ya que no ha existido formación previa ni preparación suficiente para participar plenamente, del mismo modo que se hace en actos y fiesta populares, espóntaneos u organizados, en los que cultura y comunicación están realmente al alcance de todos sin necesidad de publicidad. Entonces, ¿En qué se asemeja y cómo debemos generar ese espacio simbólico de la inclusión, de la apropiación en el seno de la Red? Nuevamente, estamos ante una incógnita que debemos resolver desde los estudios de la Información para conocer cómo afecta el sistema a nuestros hábitos, proponiendo modelos de participación que puedan ser absorbidos y determinen las tendencias y el futuro de la red desde la democracia y el control ciudadano. En ese sentido, el llamado modelo holandés o de tecnología constructiva (alentado por el $\mathrm{V}$ Programa Marco) es un ejemplo a seguir: grupos de ciudadanos participan en la creación de prototipos junto a los diseñadores.

El abordaje de estas nuevas problemáticas, como se ha esbozado, ha de realizarse a partir de posiciones transdisciplinares. Desde hace veinte años he venido trabajando en la confluencia de las disciplinas vinculadas al análisis semántico ( al fin y al cabo, los problemas de búsqueda en Internet son problemas de significado y sentido) tales como el Análisis del Discurso, la Lógica proposicional, la Semántica estructural en su convergencia con la Ingeniería del conocimiento, las ciencias cognitivas y la gestión de sistemas. Resultado de ello, es un nuevo marco para la reflexión tecnocultural y la propuesta de dispositivos sociosemánticos.

También he tomado posición por los principios y objetivos de la nueva Ciencia enunciados por la Unesco en las sucesivas Conferencias sobre nuevas fronteras del conocimiento, en gran medida identificados con ciertos elementos del pensamiento posmoderno occidental, para dar respuesta a la crisis epistemológica cuya única salida airosa para algunos ha sido, de momento, el modelo digital. Acaso los estudios de información y documentación constituyan, como dice el informatólogo alemán Gernot Wersig, las bases de una de las primeras ciencias de la posmodernidad junto a la Ecología.

La mirada cambia, se vuelve holística o, mejor, integral, en el nuevo paradigma emergente que nos anuncia Boaventura Santos. La investigación se vuelca hacia la resolución de problemas prácticos desde todos los puntos de vista posibles, desde dentro y desde fuera, implicando conscientemente al sujeto en el objeto, explicitando esa implicación como reacción a los postulados objetivistas de la ciencia moderna. El físico no puede inhibirse de las consecuencias sociales de sus experimentos ni el documentólogo olvidar el Álgebra. La base de la recuperación de información -en bases de datos y en Internet- la inventó, sin saberlo, Boole mediante unos simples operadores lógicos de unión y exclusión de conjuntos. En el holocausto, los químicos nazis que producían gases letales no debían hacerse preguntas sobre antropología física judía.

Por ello, hoy la obsesión del epistemólogo debe dirigirse hacia conglomerados de saberes, más que a ciencias y nomenclaturas artificiales, necesarios para reflexionar y resolver problemas. El neopositivismo científico nos presenta una clasificación de la ciencia y de las áreas de conocimiento que sólo funciona, y con dudosa eficacia, bajo objetivos administrativos. El optimismo tecnológico, de otro lado, tan vinculado a la Sociedad de la Información y al paradigma tecnicista que invade la investigación social se engarza fundamentalmente a objetivos mecanicistas, distantes de la significación, cuando no economicistas impulsados por el índice Nasdaq o el nuevo índice tecnológico bursátil español.

Entonces, ¿En quién debemos pensar cuando hablamos desde nuestra disciplina de Sociedad de la Información? ¿En la Bolsa o en el barrio? ¿En optimizar recursos de información para los siempre bien-informados -científicos, políticos, grandes empresarios- o en promover la educación y la cultura de la información entre los habitualmente desheredados? Y, a continuación, debemos también preguntarnos ¿Qué está haciendo y qué debe hacer nuestra disciplina al respecto?

He aquí, y ya termino, algunos itinerarios de salida para superar las contradicciones y reducciones apuntadas: conocer al usuario (como ciudadano y no como cliente) para saber de qué pasta está hecha la Sociedad de la Información; para conocer qué necesidades de información tiene y cómo las expresa; instruirle en el manejo de herramientas de telecomunicación una vez que se ha formado su capacidad de respuesta crítica y también su capacidad para la selección y la toma de decisiones; introducir estas materias en la enseñanza básica y formar a los especialistas o brokers de la información -bibliotecarios, archiveros, documentalistas- en el conocimiento de sus usuarios, es decir, dotar de una sólida formación crítica a estos mediadores que suelen operar sin reflexionar demasiado sobre lo que hacen o sus consecuencias. En suma, ante el síndrome de la información (para algunos infonoma o ansiedad provocada por sobreexposición o subexposición) debemos disponer de recursos humanos vacunados, críticos.

Hoy día, un biblitecario del Punjab puede influir en la toma de decisiones de un investigador andaluz. Para ello, la formación en Epistemología, en Teoría del Conocimiento y en el propio discurso sobre el que han de operar es 
básica. De otro modo, la investigación tecnológica usurpa el territorio de los mensajes, que no conoce ni le interesa, solucionando los problemas de significado y cultura con aparatos y programas. La tecnología, gran e indispensable aliada de la información, se encuentra en ese terreno con sus propias limitaciones dando al traste con el mito de panacea de que goza entre muchos. Porque, en los sistemas de infor- mación en red, los problemas de sentido y de cultura sólo pueden medirse con parámetros semánticos y cualitativos; sólo pueden resolverse desde la conciencia, desde la sensibilidad y desde la ética que nos imponen los contextos y los efectos sobre las personas.

(Muchas gracias) Swagat aur dhanavad
Conferencia pronunciada por el prof. Antonio García Gutiérrez en la ceremonia de recepción de la medalla de oro a la investigación concedida por la Kaula Endowment for Library Information Science de la India, que tuvo lugar en la Universidad de Sevilla el 15 de junio de 2000 (Introducción, en español, del texto publicado por la Fundación.)

\section{Antonio García Gutiérrez}

\section{Europa Nostra premia cinco proyectos españoles de conservación}

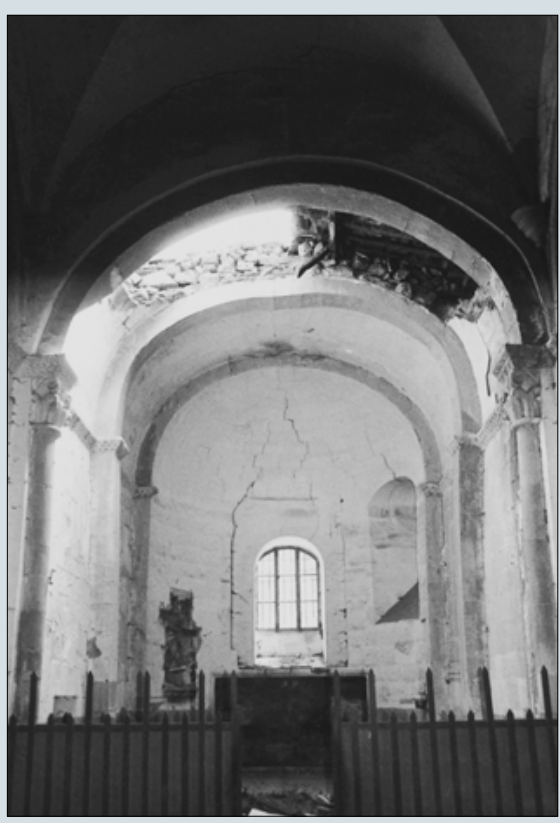

Iglesia de San Cristobal. Salamanca. (Antes)

La federación europea de defensa del patrimonio Europa Nostra ha concedido cinco diplomas a otros tantos proyectos españoles que han destacado por su contribución a la conservación y acrecentamiento del patri-

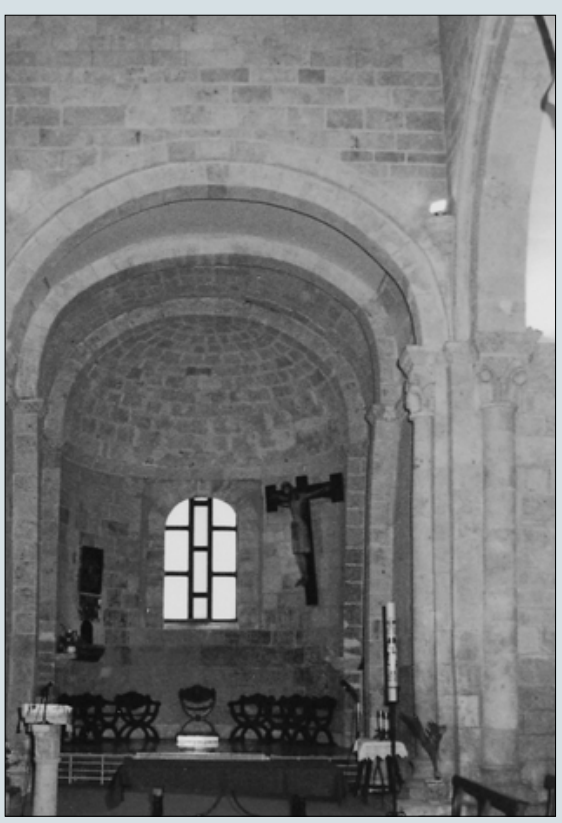

Iglesia de San Cristobal. Salamanca. (Después)

monio arquitectónico y natural en Europa, en 1999.

A la convocatoria, cuyo resultado se hizo público durante la pasada primavera en Italia, concurrieron un total de ciento veinticinco proyectos procedentes de veintidós países europeos, ejecutados tanto por el sector público como privado. Las ocho medallas y diecinueve diplomas han premiado la labor de restauración de edificios; la adaptación de viejos edificios para nuevos usos, respetando el carácter original; la restauración y conservación de parques, jardines y paisajes con valores históricos y culturales; y las nuevas construcciones respetuosas con el estilo arquitectónico o belleza natural imperantes. En el caso de nuestro país, sobresalieron los siguientes actuaciones patrimoniales:

- Casa n² 29 de la calle Bizcocheros en Jerez de la Frontera (Cádiz)

- Fortificaciones de Melilla

- Iglesia de S. Cristóbal en Salamanca

- Catedral de Santiago de Compostela

- Seo de Zaragoza

\section{Información:}

Hispania Nostra España

María Chapa

C/ Manuel $5,1^{\circ}$ piso

28015 Madrid

Tel.: 9| $5424 \mid 35 \quad$ Fax: 9| $5424 \mid 76$

\section{Fe de erratas}

Por un error en la impresión del Boletín anterior, en el artículo de la sección Tendencias titulado "La Base de Datos de Ciudades Históricas Andaluzas" no salió publicado el final del texto. Se reproduce aquí:

Para terminar, decir que aprovechando este trabajo y la publicación del Cdrom de "Inmuebles protegidos en las capitales andaluzas", se ha iniciado una campaña de actualización de los datos, toda vez que se dispone de los últimos planeamientos urbanísticos generados para la ordenación y planificación del territorio andaluz.

Este trabajo se ha desarrollado por el área de patrimonio arquitectónico y urbano del centro de documentación del IAPH, coordinado por Mariano Pérez Humanes y participando en los criterios documentales y la recopilación de información Carlos Tapia Martín y Salud Soro Cañas. 